\title{
ASSESSMENT OF TWO DIFFERENT SPLINTING MATERIALS ON THE IMMEDIATE FUNCTIONAL LOADING OF IMPLANTS PLACED IN MANDIBULAR UNILATERAL FREE END SADDLE CASES
}

\author{
Heba E. Khorshid* and Nora M. Sheta**
}

\begin{abstract}
Background: The class II Kennedy mandibular removable partial denture has many problems as the different nature of support as well as crossing the arch for stabilization. The Target of this work was to evaluate the changes that occurs in the supporting structures of the implants placed in class II Kennedy cases as a result of two different types of splinting materials.

Materials and Methods: Thirty implants were placed in ten patients with unmodified mandibular Kennedy Class II. For each patient, three implants were placed at the premolar/molar mandibular region. All the implants were immediately loaded following an Immediate Functional Loading Protocol. Patients were divided into two equal groups; Group A: received superstructures that were splinted with acrylic resin while Group B; received superstructures that were splinted with metal. Radiographic evaluation using dental CT was carried out at intervals of $0,6,12$ and 24 months after implant surgery.
\end{abstract}

Results: The results comprised the assessment of the bone height changes surrounding the three implants placed unilaterally in the posterior mandibular areas of ten patients as a result of two different splinting materials; the acrylic resin and the chrome cobalt metal alloy. Statistical analysis showed that there was a statistically significant difference in the mean bone height values along the whole study period between both groups $(\mathrm{P} \leq 0.05)$ where there was more favorable bone height values and hard tissue reaction in Group B (metal splinting) than Group A (Acrylic splinting).

Conclusion: Within the limitation of this study, it can be concluded that the rigid splinting and immobilization of immediately loaded implants by metallic superstructures reduced the transmission of micro-motion to the implant bodies and improved peri-implant bone reaction in comparison with the use of the less rigid acrylic resin material.

KEYWORDS: Class II Kennedy, rigid splinting, immediate loading, functional loading,

* Lecturer, Department of Prosthodontics, Faculty of Oral and Dental Medicine, Cairo University.

** Assistant Professor, Department of Prosthodontics, Faculty of Oral and Dental Medicine, Cairo University. 


\section{INTRODUCTION}

The natural posterior mandibular teeth continue to be lost mainly due to caries and periodontal disease. ${ }^{(1)}$ Rehabilitation of the distal extension base with conventional removable partial prosthesis usually result in movement due to the dual nature of support of teeth and mucosa with their different resiliencies. ${ }^{(2)}$ Solving this problem was done by proper distribution of load between the tooth and residual ridge mucosa. This was achieved by making functional impressions, using a wide prosthetic base within the physiologic limits of each patient and periodic relining of the prosthetic seat. ${ }^{(3)}$ Also the use of clasps or attachments with stress breaking action, splinting of the most distal teeth, reduction of the occlusal table, balancing occlusal contacts and/or the use of stress-breakers were other advocated methods. ${ }^{(3,4)}$ All these suggestions seek a common objective: to distribute the loads as axially as possible on the supporting teeth, which, theoretically, would distribute the occlusal loads to the supporting structures in the most physiological and uniform manner.

However, removable partial dentures may be associated with, compromised function, impaired aesthetics, an increased risk of caries and periodontal disease as well as poor patient acceptance to wear a removable prosthesis. ${ }^{(5-7)}$

Unilateral partial dentures used to restore unmodified Kennedy Class II cases have the added problem of lack of cross-arch stabilization, which can result in easy dislodgement and additional complications. Consequently, an RPD with crossarch stabilization or an implant-retained fixed partial denture is generally preferred which is usually poorly accepted by patients..$^{(8.10)}$

Consequently, osseointegrated implants were utilized in partially edentulous patients to overcome all the problems related to the distal extension mandibular cases. Patients can be restored by fixed, removable or fixed detachable partial dentures in patients with extensive loss of posterior teeth. (11) Additionally, Immediate loading was also performed and have attained wide acceptance among clinicians and the scientific community ${ }^{(12,13)}$ Even though the results are sometimes inconsistent, there is increasing evidence to support the procedure of immediate loading. ${ }^{(14)}$ Avila et al. ${ }^{(15)}$ summarized the advantages of immediate loading of dental implants. He stated that immediate loading of dental implants allows quick masticatory function and esthetics. In addition it also eliminates the inconvenience of a second stage surgical approach for the placement of transepithelial abutments. This often leads to early soft tissue healing and results in early stabilization of peri-implant mucosa to ensure higher implant survival.

However, Avila et al. ${ }^{(15)}$ and Suzuki et al. ${ }^{(16)}$ agreed that immediate loading of dental implants possess a higher implant failure rate due to implants micro-movement; and the inability to predict final soft and hard tissue outcomes.

In a study performed by Brunski ${ }^{17}$, it was revealed that when the impact load applied to the bone/implants interface exceeds a certain threshold, bone micro-damage followed by crestal bone loss usually occur. It was suggested by Lundgren and Laurell ${ }^{18}$ that stiff prosthetic materials might distribute the stresses more evenly to the abutments and implants. However, effects of resin material to connect implant are still controversial ${ }^{19}$ although many complications have been reported clinically. ${ }^{20}$ Additionally, It has been stressed by Nikellis et al. (21) and van Steenberghe et al. (22) that immediately loaded implants in multi-unit situations should be rigidly splinted by their superstructures.

The Target of this study was to evaluate the changes that occur in the supporting structures of immediately loaded implants placed in the posterior mandibular region using two different splinting materials of the Prosthetic superstructure; Acrylic Resin and Metal splinting. 


\section{MATERIALS AND METHODS}

Ten patients were selected from the outpatient Prosthodontics clinic, Faculty of Oral and Dental Medicine, Cairo University. Patients were selected with unilateral free end saddle (unmodified Class II Kennedy) mandibular arch, free from any systemic disease, with normal maxillo-mandibular relationship (Class I Angle classification) and no para-functional habits. The patients' mean age was 42 years. The maxillary arch was completely dentulous either by a set of natural dentition or restored with satisfactory fixed restorations.

The implants of choice in this study were the InterActive ${ }^{\mathrm{TM}}$ implants (Implant Direct Sybron International, CA 91301, USA). Each patient received three implants at the premolar/molar mandibular region over which 3-unit screw-retained fixed/detachable restorations were fabricated. Osteotomies were prepared using the classical drilling sequence (pilot, intermediate and final drills) and were irrigated with sterile saline after each drill Figure 1. An insertion torque of $30 \mathrm{Ncm}$ was checked by an adjustable torque wrench. Ostell device Resonance frequency analysis (Osstell, Gothenburg, Sweden) was used to verify that all implants reading were at least 60 before immediate loading was performed. Prophylactic Antibiotic (Augmentin, Amoxicillin/ Clavulanic Acid, 1000 mg, Glaxo-Smithkline, Beecham,Great Britain) regimen (17) in addition to an anti-inflammatory drug (Dextromethesone, $6.6 \mathrm{mg}$ in $2 \mathrm{ml}$ ) was admintered post-operatively to warrant a local antiseptic condition and to moderate any reaction from surgical trauma.

Immediately after the implant surgery was complete, the plastic transfer copings/mounts were snapped over the implants and an indirect closed tray impression technique was done. A centric jaw relationship record was also registered using the inter-occlusal wax wafer technique. Impressions were then poured using extra hard stone onto which wax patterns were constructed. Plastic burnouts (Implant Direct Sybron International, CA 91301, USA) were attached over each implant analogues by retaining screws.

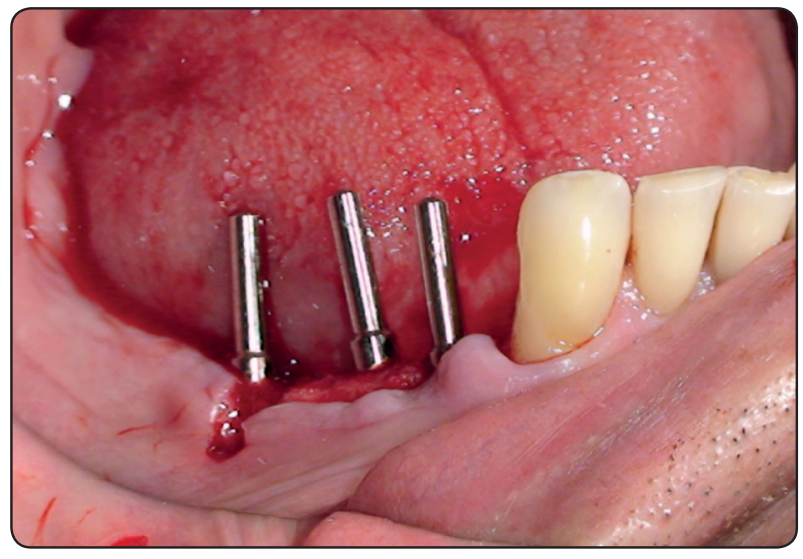

Fig. (1) Paralleling rods placed in the three osteotomies from a buccal view

At this point, patients were divided into two equal groups; Group A: received superstructures splinted with acrylic resin where the plastic burnouts were cast individually into chrome cobalt metal alloys after being waxed up (Splinting was then performed using the acrylic resin superstructure) and Group B: received superstructures splinted with metal where a wax pattern was fabricated over the three plastic burnouts producing a single piece wax pattern which was then sprued, invested then finally cast into chrome cobalt metal alloy. For group B, metal try-in of the metal frameworks was performed in the patients' mouths within twenty four hours after implant surgery using the one-screw test, ${ }^{(23)}$ the detection of any marginal gap using an explorer and enhanced lighting. The detection of any gap is an indication that sectioning and soldering was required. Figure $2 \mathrm{~A}$

In both groups, the acrylic resin was constructed to be in direct occlusal contact with the opposing maxillary teeth to achieve Immediate Functional Loading of the implants within 48 hours of the implant surgery using the following occlusal protocol: 


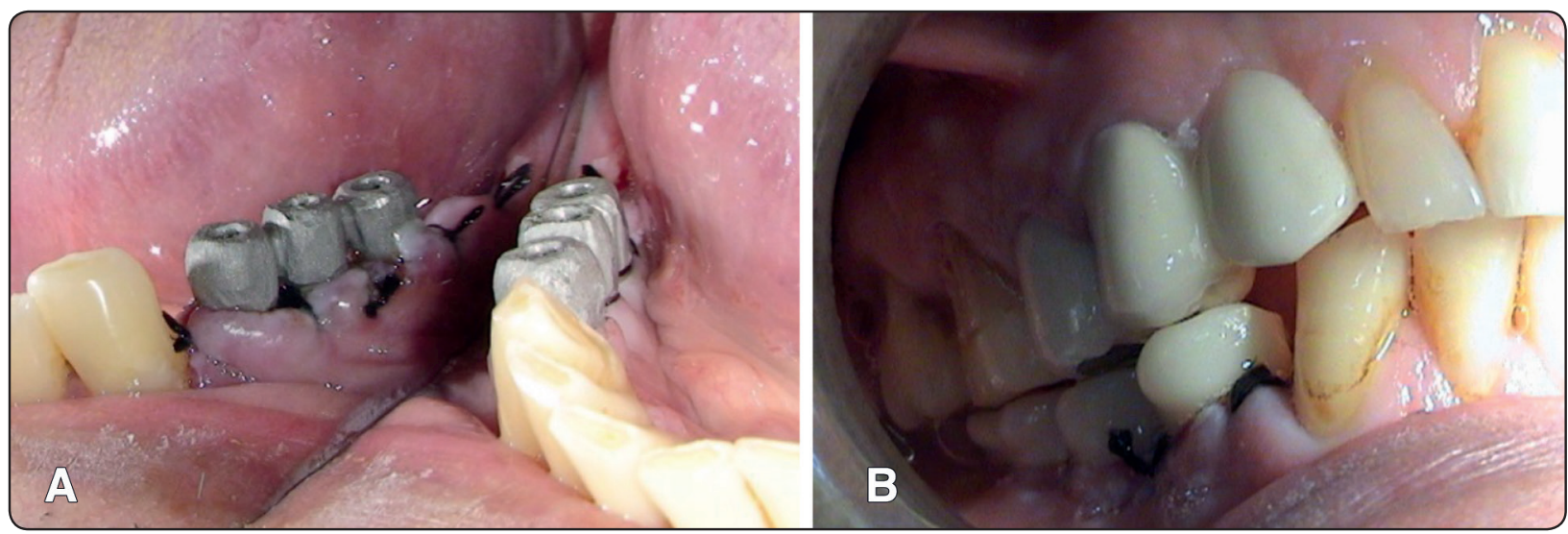

Fig. (2) A Metal framework tried in the patient's mouth and checked for fit in Group B. B: Restoration delivered in Group A after 48 hours of implant surgery

- Uniformly dispersed occlusal contacts and force.

- Wide grooves and flat fossa to achieve wide freedom in centric occlusion

Slight reduction of the cusp angle especially the buccal inclines of the mandibular buccal cusps

- Even, Smooth, lateral excursive movements without interferences.

- Narrowing the bucco-lingual and mesio-distal dimensions of the prostheses.

Moreover, the passivity of fit of the final provisional was evaluated both in the laboratory on the cast and clinically in the patient's mouth using the one-screw test for both groups. The detection of any gap is an indication that sectioning and soldering was required. Figure 2B

Radiographic Follow-Up: In this study, radiographic assessment was performed using dental Computed Tomography (CT) at zero, six, twelve and twenty-four months after surgery. After obtaining the images a computer software program (Mimics, Materialise HQ, Technologielaan 153001 Leuven, Belgium) was used, whereby coronal and saggittal reformatting and panoramic views were obtained. The crestal bone height was measured to obtain the mean of 4 readings: mid-buccal, midlingual, mid-distal and mid-mesial at each implant site for both groups. Bone height readings were then calculated, tabulated and statistically analyzed. Implants were nominated from 1 to 3 in each case where implant 1 was the most anterior, implant 2 was the middle while implant 3 is the most posterior.

\section{Statistical Methods}

The data of this trail were statistically analysed to evaluate the bone height change around the implants as a result of two different types of splinting materials. The normal distribution of parameters was tested by Shapiro-Wik test. Normally distributed continuous variable were tested using unpaired $\mathrm{T}$ student test or Anova while Paired t-test was used to study the effect of time on each group. Probability values $\leq 0.05$. All calculations were made with the DPSS software package (version 13.1: SPSS Inc)

\section{RESULTS}

The results comprised the assessment of the bone height changes surrounding the three implants placed unilaterally in the posterior mandibular areas of ten patients as a result of two different splinting materials; the acrylic resin and the chrome cobalt metal alloy. Mean values and standard deviation (SD) were calculated for each variable at the day of prosthetic loading, six months, twelve months and then two years later. 
In this study, all the patients adjusted with their prosthesis without any complaints. The prosthesis fulfilled both function and aesthetics for all the patients.

At the end of this study, a total of thirteen implants were considered successfully osseointegrated with two implant failures (implants 1 and 2 failed in patient number 4) in Group A while a total of fifteen implants were considered osseointegrated with zero implant failures in Group B. Peri-implantitis, peri-mucositis or clinical implant mobility as well as any pain noted on palpation, percussion or function were the criteria utilized that indicated the failure of any implant in this study. Lack of all of the previously mentioned criteria was a sign of successful osseointegration.

The mean values $(\mathrm{m})$ and standard deviation (St.D) of the bone height values in Groups A and B at day of loading, six, twelve month and twenty four month are shown in Table 1. Statistical analysis showed that there was a statistically significant difference in the mean bone height values along the whole study period between both groups as revealed in Table $1(\mathrm{P} \leq 0.05)$. Statistical analysis revealed that the mean bone height values and hard tissue reaction was more favorable in Group B (metal splinting) than Group A (Acrylic splinting) as shown in Table 1.

Results also revealed a statistically significant difference between the two groups $(\mathrm{p}=0.000)$ from day of loading to six month and from the day of loading to twelve months as well as from the day of loading to twenty four months. Statistical analysis thus showed that there was statistically significant less decrease in the mean bone height values in Group B (metal splinting) than in Group A (Acrylic splinting) as shown in Figure 2 and Table 2.

TABLE (1): The mean bone height values and standard deviation around the implants in both groups.

\begin{tabular}{|l|c|c|c|}
\hline \multirow{2}{*}{ Time } & Group A & Group B & P value \\
\cline { 2 - 4 } & Mean \pm SD & Mean \pm SD & $0.009 *$ \\
\hline Day of loading & $11.398 \pm 0.488$ & $10.942 \pm 0.398$ & $0.04^{*}$ \\
\hline Six month & $10.271 \pm 0.1899$ & $10.525 \pm 0.399$ & $0.005^{*}$ \\
\hline Twelve month & $9.725 \pm 0.412$ & $10.23 \pm 0.459$ & $0.001^{*}$ \\
\hline Twenty four month & $9.226 \pm 0.471$ & $9.868 \pm 0.487$ & \\
\hline
\end{tabular}

*P-values $\leq 0.05$ are considered significant

TABLE (2) The mean bone height values and standard deviation changes with time around the implants in the two groups

\begin{tabular}{|l|c|c|c|}
\hline \multirow{2}{*}{ Interval } & Group A & Group B & \\
\cline { 2 - 4 } & Mean differences $\pm \mathrm{SD}$ & Mean differences \pm SD & P-value \\
\hline From day of loading-six month & $-1.221 \pm 0.489$ & $-0.417 \pm 0.245$ & $0.00^{*}$ \\
\hline From day of loading to twelve month & $-1.768 \pm 0.051$ & $-0.712 \pm 0.340$ & $0.00^{*}$ \\
\hline From day of loading to twenty four month & $-2.267 \pm 0.58$ & $-1.0736 \pm 0.278$ & $0.00^{*}$ \\
\hline
\end{tabular}

$* P$-values $\leq 0.05$ are considered significant 


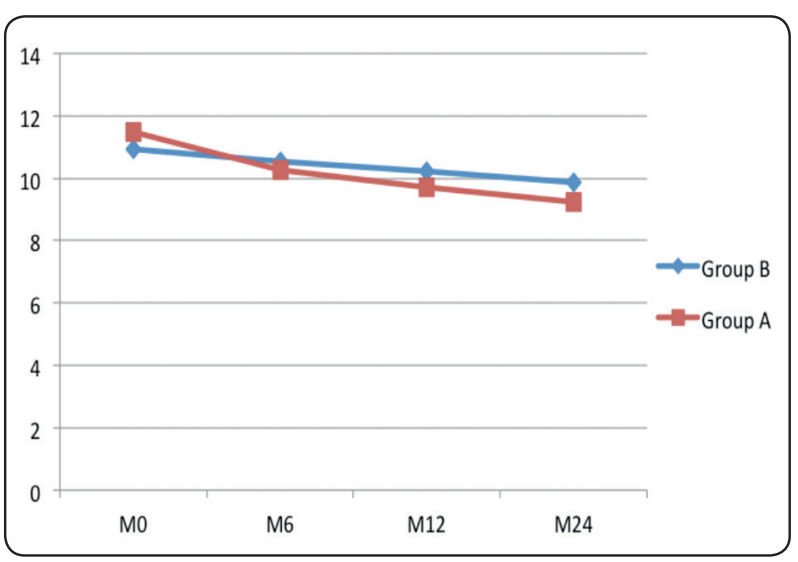

Fig. (3) The mean bone height values and standard deviation changes with time around the implants in the two groups .

\section{DISCUSSION}

This clinical study's main purpose was to assess the effect of two different prosthetic splinting materials on immediately loaded implants placed in the posterior mandibular region. In the past, fibrous encapsulation around immediately loaded implants was a common finding due to a variety of reasons such as poor implant materials, lack of understanding of the mechanical aspect of implant loading, bone-implant interface and healing, lack of proper occlusion, inadequate prosthetic design and material as well as inferior surface configuration and thread design ${ }^{(17)}$. One of the major reasons behind failures of immediately loaded dental implants and lack of osseointegration was the transmission of micro-motion to the body of the implant during the healing process as stated by Romanos ${ }^{(24)}$ and Degidi and Piattelli ${ }^{(25)}$. The authors highly indicated that the primary stability and immobilization of dental implants is the most important factor influencing the clinical success of immediately loaded implants. Consequently, Lundgren and Laurell (18) suggested that stiff prosthetic materials might distribute the stresses more evenly to the abutments and implants and avoid these micro-movements. For this reason, it was wise to study and analyze the long-term consequences of two different prosthetic superstructure splinting materials; the acrylic resin and the chrome cobalt metal alloy, on the supporting structures and survival of immediately loaded dental implants placed in the posterior mandibular region.

In this current study, statistical analysis showed that there were a statistically significance differences in the mean bone height values along the whole study period between both groups where the mean bone height values and hard tissue reaction was more favorable in Group B (metal splinting) than Group A (Acrylic splinting). This was in agreement with a study performed by Nkenke et al. ${ }^{(26)}$ who realized that in the majority of cases, the reduction of the vital bone-to-implant contact can be compensated effectively by the rigid splinting fixation, thus decreasing the stresses along the developing multiple interfaces and increasing the stability, retention, and strength of the transitional prosthesis during the initial healing phase. Accordingly, it was concluded by several authors that splinted implants may decrease the risk of overload to each implant as a result of greater surface area and better biomechanical load distribution. ${ }^{(27,28)}$

Results of this study also revealed a statistically significant difference between the two groups $(\mathrm{p}=0.000)$ from the day of loading to six month and from the day of loading to twelve months as well as from the day of loading to twenty four months. Statistical analysis thus showed that there was statistically significant less decrease in the mean bone height values in Group B (metal splinting) than in Group A (Acrylic splinting). This can be explained by the fact that the rigid splinting and immobilization of immediately loaded implants by rigid metallic superstructures reduced the transmission of micro-motion to the implant bodies, improved the implant stability and minimized distortional strains on the peri-implant tissues hence improved peri-implant bone reaction. This was in agreement with Nikellis et al. ${ }^{(21)}$ and van Steenberghe et al. ${ }^{(22)}$ who stressed that immediately loaded implants in multi-unit situations should be rigidly splinted by their superstructures. The use of less rigid materials as Acrylic resin flexes with biting force and thus transmits unfavorable shear forces to the bone-implant interface due to the poor 
mechanical properties of acrylic resin ${ }^{(28)}$. Hassan et al. ${ }^{(30)}$ added that by splinting the implants, the stress on the implant system was reduced from $5393 \mathrm{MPa}$ to $2942 \mathrm{MPa}$. Furthermore, Holst et al. (31) recommended that in order to optimize splinting, metal reinforced superstructures was recommended to help confine the occlusal forces within the physiological micro-motion threshold limit which was determined by Szmukler-Moncler et al. ${ }^{(32)}$ to be $50-150 \mu \mathrm{m}$.

\section{CONCLUSION}

Within the limitation of this study, it can be concluded that the rigid splinting and immobilization of immediately loaded implants by metallic superstructures reduced the transmission of micromotion to the implant bodies and improved periimplant bone reaction in comparison with the use of the less rigid acrylic resin material. The use of metal reinforced prosthetic materials seems to distribute the stresses in a more even and uniform manner to the abutments and bone/implant interface.

\section{REFERENCES}

1. Rocha, E.P., Luersen, M.A., Pellizzer, E.P., Distalextension removable partial denture associated with an osseointegrated implant. Study by the finite element method. J. Dent. Res. 2003; 82:B-254.

2. Chou, T.M., Eick, J.D., Moore, J.D., Stereophotogrammetric analysis of abutment tooth movement in distal-extension removable partial dentures with intracoronal attachments and clasps, J. Prosthet. Dent. 1991; 66:343-349.

3. El Charkawi, H.G., El Wakad, MT.; Effect of splinting on load distribution of extracoronal attachment with distal extension prosthesis in vitro. J. Prosthet. Dent. 1996; 76:315-320.

4. Itoh, H., Caputo, A.A., Wylie, R.; Effects of periodontal support and fixed splinting on load transfer by removable partial dentures. J. Prosthet. Dent. 1998; 79:465-471.

5. Vermeulen AH, Keltjens HM, van't Hof MA, et al.; Tenyear evaluation of removable partial dentures: Survival rates based on retreatment, not wearing and replacement. J Prosthet Dent. 1996; 76: 267.
6. Zlataric DK, Celebic A, Valentic-Peruzovic M.; The effect of removable partial dentures on periodontal health of abutment and non-abutment teeth. J Periodontol. 2002; $73: 137$.

7. Liedberg B, Stoltze K, Owall B.; The masticatory handicap of wearing removable dentures in elderly men. Gerodontology; 2005; 22:10.

8. Barker D, Cooper A. A novel use of a unilateral hinged partial denture. Br Dent J. 2006;201: 571.

9. Carr AB, McGivney GP, Brown DT. Principles of removable partial denture design. In: McGivney GP, Castleberry DJ, eds. McCracken's Removable Partial Prosthodontics. 9th ed. St Louis, MO: Mosby 1995;157.

10. Ganz SD. The replacement of a unilateral partial denture with an implant supported fixed prosthesis: a clinical report. Imp Dent. 1998;7: 159.

11. Verri, F.R., Pellizzer, E.P., Rocha, E.P. and Pereira, J.A., ;Influence of Length and Diameter of Implants Associated With Distal Extension Removable Partial Dentures; Imp Dent 16: 2007; 275-280,.

12. Gapski R, Wang HL, Mascarenhas P, Lang NP. Critical review of immediate implant loading. Clin Oral Impl Res. 2003; 14:515-527.

13. Capelli M, Esposito M, Zuffetti F, Galli F, Del Fabbro M, Testori TA. 5-year report from a multicentre randomized clinical trial: immediate non-occlusal versus early loading of dental implants in partially edentulous patients. Eur J Oral Implantol. 2010; 3;209-219.

14. Esposito M, Grusovin MG, Coulthard P, Worthington HV. Different loading strategies of dental implants: a Cochrane systematic review of randomized controlled clinical trials. Eur J Oral Implantol. 2008;1:259-276.

15. Avila, G; Galindo, P; Rios, H; Wang, H: Immediate Implant Loading: Current Status From Available Literature. Implant Dentistry. 2007; 16(3):235-245.

16. Suzuki, J.B., Misch, C.E., Sharawy, M., Sarnachiaro, O.J., Sarnachian, G.O.,Mota, L., Arana, G.,Gotta, S.L., Gotta, E. and Bui, L.; Clinical and histological evaluation of Immediate -Loaded Posterior Implants in Nonhuman Pirates; Impl. Dent. 2007; 16, 2 ;176-183,

17. Brunski JB. Biomaterials and biomechanics in dental implant design. Int J Oral Maxillofac Implants 1988;3:8597. 4. 
18. Lundgren D, Laurell L. Biomechanical aspects of fixed bridgework supported by natural teeth and endosseous implants. Periodontology 2000;4:23-40.

19. Skalak R. Biomechanical considerations in osseointegrated prostheses. J Prosthet Dent 1983; 49:843-848.

20. Babbush CA, Kirsch A, Mentag PJ, Hill B. Intramobile cylinder (IMZ) two-stage osteointegrated implant system with the intramobile element (IME): Part I. Its rationale and procedure for use. Int $\mathrm{J}$ Oral Maxillofac Implants 1987; 2:203-216

21. Nikellis, I., Levi, A. \& Nicolopoulos, C.; Immediate loading of 190 endosseous dental implants: a prospective observational study of 40 patient treatments with up to 2-year data. International Journal of Oral \& Maxillofacial Implants 2004; 19: 116-123. 47.

22. Van Steenberghe, D., Molly, L., Jacobs, R., Vandekerckhove, B., Quirynen, M. \& Naert, I.; The immediate rehabilitation by means of a ready-made final fixed prosthesis in the edentulous mandible: a 1-year follow-up study on 50 consecutive patients. Clinical Oral Implants Research 2004; 15: 360-365.

23. Sahin, S. and Cehreli M. C. The significance of passive framework fit in implant prosthodontics: current status. Implant Dent. 2001; 10(2): p. 85-92.

24. Romanos, G.E.; Present status of immediate loading of oral implants. J. Oral Implantol. 2004; 30:189-197.

25. Degidi, M., Piattelli, A.; 7-year follow-up of 93 immediately loaded titanium dental implants. J. Oral Implantol. 2005; 31:25-31.
26. Nkenke, E., Lehner, B., Weinzierl, K., Thams, U., Neugebauer, J., Steveling, H., Radespiel-Troger, M., Neukam, F.W.; Bone contact, growth, and density around immediately loaded implants in the mandible of mini pigs. Clin. Oral Impl. Res. 2003; 14,: 312-32.

27. Matsuzaka, K., Nakajima, Y., Soejima, Y.,; Effect on the amount of bone-implant contact when splinting immediateloaded dental implants. Implant Dent. 2007; 16:309-316.

28. Draggo, C.J., Lazzara, R.J.; Immediate occlusal loading of osseotite implants in mandibular edentulous patients: A prospective observational report with 18-month data. J Prosthodont. 2006; 15:187-194.

29. Khorshid, H E, Hamed, H A, Aziz, EA.; Complications, Risk Factors, and Failures of Immediate Functional Loading of Implants Placed in the Completely Edentulous Maxillae: A Report of 3 Consecutive Cases. Impl Dent; 2014; 23(2), 125-131

30. Hasan I, Bourauel C, Keilig L, Stark H, Lückerath W., The effect of implant splinting on the load distribution in bone bed around implant-supported fixed prosthesis with different framework materials: A finite element study.; Ann Anat. 2015; 199:43-51.

31. Holst, S., Geiselhoeringer, H., Wichmann, M., Holst, A.I.; The effect of provisional restoration type on micromovement of implants J. Prosthet. Dent. 2008; 100:173-182.

32. Szmukler-Moncler, S., Salama, H., Reingewirtz, Y. \& Dubruille, J.H.; Timing of loading and effect of micromotion on bone-dental implant interface: review of experimental literature. Journal of Biomedical Materials Research 1998; 43: 192-203. 